\title{
Mouse models of altered gonadotrophin action: insight into male reproductive disorders
}

\author{
Kim C Jonas ${ }^{1}$, Olayiwola O Oduwole ${ }^{1}$, Hellevi Peltoketo ${ }^{2}$, Susana B Rulli ${ }^{3}$ and \\ Ilpo T Huhtaniemi ${ }^{1,4}$
}

${ }^{1}$ Department of Surgery and Cancer, Institute of Reproductive and Developmental Biology, Imperial College London, Du Cane Road, London W12 ONN, UK, ${ }^{2}$ Biocenter Oulu, University of Oulu, PO Box 5000, FI-90014 Oulu, Finland, ${ }^{3}$ Instituto de Biología y Medicina Experimental-CONICET, Vuelta de Obligado 2490 (1428), Buenos Aires, Argentina and ${ }^{4}$ Department of Physiology, University of Turku, Kiinamyllynkatu 10, FI-20520 Turku, Finland

Correspondence should be addressed to K C Jonas; Email: k.jonas@imperial.ac.uk or to be I T Huhtaniemi; Email: ilpo.huhtaniemi@imperial.ac.uk

\begin{abstract}
The advent of technologies to genetically manipulate the mouse genome has revolutionised research approaches, providing a unique platform to study the causality of reproductive disorders in vivo. With the relative ease of generating genetically modified (GM) mouse models, the last two decades have yielded multiple loss-of-function and gain-of-function mutation mouse models to explore the role of gonadotrophins and their receptors in reproductive pathologies. This work has provided key insights into the molecular mechanisms underlying reproductive disorders with altered gonadotrophin action, revealing the fundamental roles of these pituitary hormones and their receptors in the hypothalamic-pituitary-gonadal axis. This review will describe GM mouse models of gonadotrophins and their receptors with enhanced or diminished actions, specifically focusing on the male. We will discuss the mechanistic insights gained from these models into male reproductive disorders, and the relationship and understanding provided into male human reproductive disorders originating from altered gonadotrophin action.

Reproduction (2014) 148 R63-R70
\end{abstract}

\section{Introduction}

The precise control of the hypothalamic-pituitarygonadal axis is essential for coordinating and maintaining reproductive functions. In response to the pulsatile release of hypothalamic gonadotrophin-releasing hormone $(\mathrm{GnRH})$, the synthesis and secretion of the pituitary gonadotrophic hormones, luteinising hormone (LH) and follicle-stimulating hormone (FSH), modulate testicular function through the binding and activation of the gonadotrophin receptors, $\mathrm{LH} /$ chorionic gonadotrophin receptor (LHCGR) (the luteinising hormone/ chorionic gonadotrophin receptor, abbreviated as LHCGR, is the official gene, derived from the two endogenous ligands of LHR, LH and chorionic gonadotrophin (CG), in CG secreting species e.g., humans and horses) and $\mathrm{FSH}$ receptor (FSHR) respectively. The downstream activity of the gonadotrophin receptors is critical for initiation and maintenance of gonadal steroidogenesis and for support, production and maturation of viable germ cells. Our understanding of gonadotrophic hormone/gonadotrophin receptor biology has been greatly enhanced by the generation and study of genetically modified (GM) mouse models. The advent of GM mouse models, with their relative ease in generation, coupled with short gestation time and life cycle relative to larger mammalian species, has provided a powerful tool to study reproductive disorders. Moreover, the study of GM mouse models has provided key molecular insight into the causality and contributions of gonadotrophic hormones and their cognate receptors to human reproductive pathologies. A number of GM approaches have been taken to understand the molecular mechanisms governing reproductive pathologies; gain-of-function approaches have utilised the overexpression of gonadotrophins or the generation of constitutively activating mutations (CAMs) of gonadotrophin receptors, while lossof-function approaches have relied upon knockout technology to remove/silence gonadotrophin receptor or gonadotrophin gene expression. This review will describe GM mouse models with direct genetic modifications in gonadotrophin subunits or gonadotrophin receptors. We will discuss the implications of these findings on male reproductive function, and the important insights these models provide into human health and disease. 


\section{GM models of altered gonadotrophin action}

The functional role of the testis is twofold: the production of male gametes and androgen support, primarily through testosterone secretion for local androgenic action, for stimulation and maintenance of spermatogenesis and extra-gonadal sexual and anabolic functions (Sharpe et al. 1994, McLachlan et al. 1995). In the postnatal mouse, the coordinated and temporal release of the gonadotrophins, $\mathrm{LH}$ and $\mathrm{FSH}$, are required for the differentiation and maturation of the testis and extragonadal sex organs; LH is necessary for the production and secretion of testosterone via the Leydig cells, although minimal tonic testosterone production is observed in the absence of LH/LHR function, while FSH is responsible for the maintenance of spermatogenesis by stimulation and maintenance of a multitude of Sertoli cell functions.

\section{Enhanced $L H-L H R$ activity}

To examine the effects of promiscuous LHR activation, our laboratory generated two transgenic mouse models with enhanced LH/human chorionic gonadotrophin (hCG) action. The first model generated expressed the hCG $\beta$ ( $\operatorname{Tg}(\mathrm{UBC}-\mathrm{CGB}) 1 \mathrm{Hht}$ ) subunit under the human ubiquitin $C$ promoter, allowing ubiquitous, persistent and low-level expression of hCG $\beta$ from late gestation onwards (Rulli et al. 2003). The rationale behind this was that when the transgene was coexpressed in pituitary gonadotroph and thyrotroph cells with the glycoprotein hormone common $\alpha$-subunit (CGA $(\alpha G S U)$ ), bioactive heterodimers hCG $\alpha \beta$ would be produced. We termed this model hCG $\beta$, and in males, it attained moderately three- to fourfold elevated levels of bioactive hCG compared with endogenous LH (Rulli et al. 2003). hCG $\beta+$ males were fertile with full spermatogenesis and normal sperm quality despite reduced testis size and serum FSH (Rulli et al. 2003), echoing the phenotype observed in activating LHR mutations in humans. However, the onset of puberty was normal, with no evidence of precocious puberty, which is the hallmark of human males with enhanced LHR activation (Themmen \& Huhtaniemi 2000). As modest elevation in LH/hCG action had no effect on fertility or the timing of puberty, we went on to test the effect of grossly elevated LH/hCG on these factors. To achieve this, we generated another mouse model expressing the $\alpha \mathrm{GSU}$, also under the human ubiquitin $C$ promoter, and crossed with the hCG $\beta+$ mice, creating a double transgenic line $(\mathrm{hCG} \alpha \beta+)$, with a 1000-fold higher circulating concentration of bioactive LH/hCG observed when compared with WT mice (Rulli et al. 2003). hCG $\alpha \beta+$ males were infertile, despite exhibiting comparable spermatogenesis as evidenced by histological analysis of testis and caudal epididymal sperm motility and morphology to hCG $\beta+$ and WT littermates. Infertility appeared to be mechanical and/or behavioural in origin, with hCG $\alpha \beta+$ males displaying extremely aggressive behaviour, often resulting in severe injury or death of WT females housed with the males, and mating ability impaired as evidenced by the lack of vaginal plugs during breeding studies. Testes size was smaller with enlarged seminal vesicles and prostate, dilated vasa deferentia and bladder, as well as kidney defects in adulthood (Rulli et al. 2003). Testicular steroidogenesis was also enhanced, despite a near-total down-regulation of cell surface LHR expression, echoing studies showing that $<0.1 \%$ occupation of LHR is required for full testicular steroidogenesis (Mendelson et al. 1975). As with hCG $\beta+$ males, precocious puberty was not detected in hCG $\alpha \beta+$ males, despite highly elevated serum testosterone with the timing of the balano-preputial separation and onset of spermatogenesis indistinguishable from WT males (Ahtiainen et al. 2005). Interestingly, juvenile hCG $\alpha \beta+$ males developed Leydig cell adenomas, reaching their maximum size at 10 days post partum but disappearing by puberty, coinciding with the normal regression pattern of foetal Leydig cells. The gene expression of foetal and adult Leydig cell markers suggested that the adenomas originated from the foetal Leydig cell population, providing evidence that the adult Leydig cells may be resistant to developing gonadotrophin-induced adenomas (Ahtiainen et al. 2005).

Recent studies of the hCG $\alpha \beta+$ animals have revealed that the hypothalamic function of prepubertal males was altered, displaying accelerated $\mathrm{GnRH}$ pulse frequency and increased GnRH content of GnRH neurons, coupled to decreased pituitary expression of GNRHR (Gonzalez et al. 2011). A profound and persistent malfunction of the neuroendocrine feedback control of the gonadotrophin axis was evidenced, with FSH levels persistently low throughout life and unresponsive to castration or the anti-androgen flutamide both pre- and postpubertally, but with re-establishment by blockade of perinatal androgen action (Gonzalez et al. 2011). These findings suggest that androgen excess, during a critical window between gestational day 18 and postnatal day 14 , is able to disrupt the developmental programming of the male hypothalamic-pituitary-gonadal axis. A direct testosterone-dependent regulation of hypothalamic aromatase expression was also demonstrated, indicating that locally produced oestrogens might play a key role in the hypothalamicpituitary phenotype of hCG $\alpha \beta+$ mice.

Additional GM models to test the effects of elevated hCG or LH have also been utilised by others. A transgenic model overexpressing hCG $\beta$ expressed under the metallothionein (MT1) promoter did not show elevated circulating dimeric hCG nor obvious changes in testicular phenotype, yet MT1-hCG $\beta$ males were infertile, speculated to be due to free circulating hCG $\beta$ subunit binding to LHR and competing with endogenous LH for receptor occupancy (Matzuk et al. 2003). Coexpression of MT1-hCG $\alpha$ and hCG $\beta$ subunits was 
conducted, to form the active hCG heterodimer. Male mice with low expression of MT1-hCG $\alpha \beta$ were initially fertile and indistinguishable from WT littermates. However, by $6-7$ months, these mice were progressively infertile but no histological abnormalities were observed and no obvious phenotypic explanation was available to indicate the cause of infertility. Male mice with high expression of the MT1-hCG $\alpha \beta$ transgenes, as with ubiquitin C-expressed hCG $\alpha \beta$ male mice, were infertile, the origin of which appearing to be through disrupted mating behaviour as evidenced by the lack of vaginal plugs when housed with either super-ovulated or naturally cycling female mice. Male mice were also noted to be aggressive when caged with other male or female mice, and displayed altered sexual behaviour. Serum testosterone was highly elevated, and circulating gonadotrophins decreased. Testis size was reduced, and histological analyses indicated Leydig cell hyperplasia and in some tubules Sertoli cell-only-like syndrome, with germ cell loss, echoing observation of LHR overactivity in humans. A transgenic model for elevated $\mathrm{LH}$ consisting of a fusion protein of the bovine $\mathrm{LH} \beta$ subunit and the hCG $\beta$ C-terminal peptide (bLH $\beta$-CTP) under the common $\alpha$-subunit promoter has also been studied. However, this model failed to produce sufficiently elevated LH/hCG bioactivity in male animals, as they presented with no apparent phenotype (Risma et al. 1995).

To constitutively activate LHR, a novel transgenic approach using covalently linked hCG $\beta$ and $\alpha \mathrm{GSU}$ to reconstitute heterodimeric hCG, fused to rat LHR expressed under inhibin $\alpha$ subunit promoter, termed 'yoked' LHR (YHR), was utilised (Meehan et al. 2005, Meehan \& Narayan 2007). In pre-pubertal males, enhanced LH/LHR action was observed, with increased circulating testosterone and seminal vesicle weights, probably due to the early expression of the transgene driven by the inhibin $\alpha$ promoter. However, despite this elevation in testosterone, as with the hCG $\beta+$ and $\mathrm{hCG} \alpha \beta+$ animals, the timing of puberty was normal. After puberty, there was a trend for enhanced LHR action, with decreased seminal vesicle weights and reduced testis size due to a decrease in seminiferous tubule volume. However, normal spermatogenesis was noted. As with hCG $\beta+$ animals, serum FSH was suppressed in both pre- and postpubertal animals; however, LH was only suppressed in pre-pubertal animals. This defect may be the consequence of dysregulation in hypothalamic-pituitary communication and may reflect differences in the regulation of $\mathrm{LH}$ and FSH secretion.

To date, a single CAM LHR mouse model has been described, the result of a knockin D582G LHR mutation, the most commonly observed CAM in human boys with familial male-limited precocious puberty (McGee \& Narayan 2013). As with the human mutation, D582G LHR resulted in precocious puberty, with decreased testis weight and increased seminal vesicle weight at 3 weeks post partum. Serum and intra-testicular testosterone were increased from day 7 post-partum; however, serum $\mathrm{FSH}$ and $\mathrm{LH}$ remained below the limit of detection throughout the tested lifespan of the animals, due to steroid hormone feedback. Sertoli cell development was unaltered; however, Leydig cell hyperplasia was observed, with enhanced expression of steroidogenic genes in most age groups tested. Although precocius puberty was observed, spermatogenesis was not altered in these male mutants. Although initially fertile, progressive infertility was detected, but normal levels of epididymal sperm were noted, indicating a potential abnormality in seminal vesicle and prostate function and/or lower urinary tract; however, detailed analysis of accessory gland function was not carried out.

\section{Enhanced FSH-FSHR activity}

GM mouse models with elevated FSH have been generated to explore enhanced ligand-dependent activation of FSHR. As with MT-hCG $\beta$ and MT-hCG $\alpha \beta$, Kumar et al. took the approach of overexpressing human $\alpha \mathrm{GSU}$ and the human FSH $\beta$ subunit under the MT1 promoter. The MT1- $\alpha \mathrm{GSU}$ and MT1-FSH $\beta$ transgenic mice were fertile. Inter-crossing of these transgenic mouse strains generated mice overexpressing dimeric FSH (MT1-FSH $\alpha \beta)$, with high levels of circulating FSH. Male mice were largely infertile, with just one in ten animals producing one litter of pups in a 6 month period. Mating studies suggested a lack of mating activity in these animals. Testicular size and morphology were indistinguishable from WT; similarly, epididymal weights were comparable. However, serum testosterone was elevated and seminal vesicles enlarged, due to increased androgenic action. Histological analysis of the testes showed little difference from WT; moreover, analysis of epididymal sperm numbers showed MT1-FSH $\alpha \beta$ animals to have increased sperm number, with no difference in motility or viability. These findings suggest that the infertility observed in MT1-FSH $\alpha \beta$ animals appears to result from behavioural changes rather than a direct impact on spermatogenesis. It is possible that the increase in testosterone resulted in altered and/or aberrant seminal vesicle secretions, or functional incompetence of the sperm.

Mouse models of enhanced FSHR activity have primarily utilised the $h p g$ mouse model as a background in which to generate the mutations. The hpg mouse, resulting from a naturally occurring deletion mutation in Gnrh1 (Cattanach et al. 1977), with a phenotype of hypogonadotrophic hypogonadism, provides the advantage of testing the effects and direct contribution of FSH/ FSHR-dependent testicular function, in the absence of circulating LH and activation of LHR. Using the rat androgen-binding protein promoter for specific integration into Sertoli cells, Haywood et al. (2002) 
created a transgenic line expressing the human Asp567Gly FSHR CAM (TG-FSHR+). Testicular expression was confirmed, and enhanced ligand-independent cAMP production was detected in cultured TG-FSH+ Sertoli cells. In a WT background, testis weights and fertility were comparable between TG-FSH + animals and WT littermates. However, in the hpg background, testis weights were significantly increased in comparison to hpg littermates; moreover, treatment with testosterone at equivalent levels to the maximum observed in $h p g$ mouse testis vastly increased testis size in hpg TG-FSH+ animals in comparison to hpg littermates. Histological analysis of the testes showed the presence of both round and elongated spermatids, and examination of Sertoli cell structure showed the maturation of this cell type. Although intra-testicular testosterone was increased in hpg TG-FSHR + animals, serum testosterone was not different from $h p g$ littermates. A similar phenotype was also observed in a transgenic model overexpressing complete FSH ( $\alpha \mathrm{GSU}$ and FSH $\beta$ subunits) in a WT or hpg mouse background (Allan et al. 2001), demonstrating that without $\mathrm{LH}$-induced testosterone production, FSH/FSHR activity is sufficient for Sertoli cell maturation and can promote spermatogenesis to some extent. However, LH/LHR activity, and consequential testosterone production, is required for the completion of spermiogenesis.

In our laboratory, a knockin constitutively activating mFshrD580H mouse model has been generated (Oduwole/Peltoketo personal communications). Interestingly, despite this mutation having deleterious effects on female reproduction (Peltoketo et al. 2010), male animals did not present with any obviously altered phenotype during embryogenesis, puberty or adulthood. The gross morphology and histology of the reproductive tract and testis appeared no different to WT littermates, indicating that enhanced FSHR activity alone in the WT background, as opposed to hpg mice, had neither positive nor deleterious effects on male reproductive function.

\section{Diminished LH-LHR activity}

The first GM approach exploring the effects of loss of function of gonadotrophins utilised deletion of $\alpha G S U$. Deletion of the $\alpha G S U$ gene in male mice showed normal pre-natal and pre-pubertal sexual differentiation and gonadal development, confirming that pre-pubertal gonadal development in mice is independent of gonadotrophin action (Kendal et al. 1995). However, male animals, being also hypothyroid, failed to undergo puberty and exhibited a lack of sex steroid production. Post-pubertal animals lacked gonadal development and function, with diminished testis size and smaller seminiferous tubules, and spermatogenesis blocked at the first meiotic division. The presence of vas deferens and epididymis showed that the $\alpha G S U \mathrm{KO}$ mice were able to produce sufficient testosterone in utero. As the $\alpha G S U$ gene is an integral part of both heterodimeric thyroid-stimulating hormone (TSH) and FSH, it should be noted that phenotypic effects observed from deletion of $\alpha G S U$ are not the result of lacking just $\mathrm{LH}$ action, but also TSH and FSH action. The mouse model demonstrated that mice devoid of glycoprotein hormone production are viable, which is perhaps not unsurprising given that mice do not express or secrete placental CG, and rather rely upon placental lactogens and alternative hormonal support for maintenance of pregnancy, in contrast to humans in whom hCG is vital.

To decipher the effects of deleting $L h r$, our laboratory took the approach of generating an Lhrknockout (LuRKO) mouse. As with the $\alpha G S U$ knockout mice, $L h r$ deletion resulted in alterations of the reproductive tract from the pubertal period onwards, exhibiting normal pre-pubertal development (Zhang et al. 2004). Elevated FSH and LH were observed, with a decrease in sex steroid concentrations, due to lack of steroid feedback to the hypothalamic-pituitary axis (Pakarainen et al. 2007). Adult LuRKO males were infertile with underdeveloped testes and hypoplastic accessory sex organs. Testes were cryptorchid and significantly reduced in size, with narrow seminiferous tubules, decreased number and size of Leydig cells and arrested spermatogenesis at the round spermatid stage. The expression of Leydig cell-specific genes, while similar at birth, became gradually low or undetectable in adulthood. Accessory sex organs, including the prostate and seminal vesicles, were undetectable (Lei et al. 2001, Zhang et al. 2001). A similar phenotype to the LuRKO mice was also observed with the deletion of LHB, mimicking the reproductive phenotypes displayed in aGSU null male mice (Ma et al. 2004); however, LHB knockout males exhibited unaltered serum $\mathrm{FSH}$, contrasting from the hypogonadotrophic and hypergonadotrophic phenotypes of aGSU and LuRKO male mice respectively.

An interesting difference that exists between human and mouse inactivating LHR mutations, is that normal pre-pubertal development is observed in male mice; however, in human counterparts, complete inactivation of LHR results in pseudohermaphroditism (Themmen \& Huhtaniemi 2000). This indicates that $\mathrm{LH}$ action in utero is not a prerequisite for foetal Leydig cell androgen and insulin-like growth factor 3 production required for intrauterine testicular development and descent and masculinisation in male mice, highlighting the presence of additional safety mechanisms present for maintaining foetal Leydig cell function by a network of paracrine factors (El-Gehani et al. 1998, Themmen \& Huhtaniemi 2000, Peltoketo et al. 2011).

Testosterone replacement therapy in LuRKO animals leads to partial reversal of the hypogonadal phenotype, with achievement of full spermatogenesis; however, male mice remained sub-fertile due to poor accessory gland development and poor sexual behaviour 
(Pakarainen et al. 2005). Abnormalities such as vigorous inflammation of the epididymis and the prostate were conspicuous in a proportion of the testosterone-treated mice. The incidence of low ejaculatory frequency and low sperm count in cauda epididymides were also observed. Whether or not testosterone replacement, or lack of sufficient androgen priming prepubertally before testosterone replacement, is responsible for these abnormalities is not, however, clear. A striking physiological finding in the LuRKO mice is a late-onset recovery of qualitatively full spermatogenesis at $\sim 12$ months of age, when the passage of round spermatids to elongated spermatids can be found. This suggests that spermatogenesis can proceed qualitatively to completion with support of the basal $\mathrm{LH}$-independent low intra-testicular testosterone present in the LuRKO testis (Zhang et al. 2003), though a much higher threshold of testosterone may be required to induce qualitatively and quantitatively full spermatogenesis (Huhtaniemi et al. 2006). This finding was confirmed and extended in our recent study (Oduwole et al. 2014), observing that a narrow margin separated the testosterone doses that activated peripheral male sexual androgen action and spermatogenesis. When extrapolated to humans, this may jeopardise the current approach to hormonal male contraception, as it will be practically impossible to define a single dose of testosterone that can suppress gonadotrophins and attain azoospermia. Therefore, it is only a total abolition of intra-testicular testosterone action that can bring about total and complete suppression of spermatogenesis.

\section{Diminished FSH-FSHR activity}

Targeted ablation of bioactive FSH was achieved through deletion of exons 1 and 2 and partial deletion of exon 3 of FSH $\beta$ (Kumar et al. 1997). Phenotypic examination of $F s h b(F S H \beta) \mathrm{KO}$ males showed reduced testis size, with decreased seminiferous tubule diameter and volume. However, Leydig cell populations were unaffected and speculated qualitatively to be enhanced in number, however, net Leydig cell number probably did not differ from WT littermates due to the reduced testis size. Accessory sex glands were of comparable size to age-matched littermates, consistent with comparable circulating serum testosterone and adequate Leydig cell number and function. Epididymal sperm were decreased by $75 \%$ in comparison to heterozygous and WT littermates, with motility decreased by $40 \%$; however, no difference in viability was observed. Despite this, Fshb KO animals were fertile, with normal serum $\mathrm{LH}$, probably reflecting negative feedback from circulating testosterone. The maintenance of spermatogenesis and Sertoli cell function in the absence of $\mathrm{FSH}$-activated FSHR is suggestive of potential testicular or extratesticular paracrine factors that can compensate for FSH function in the testis, or that basal constituitive ligand-independent FSHR activity is sufficient to maintain tonic testis function and spermatogenesis in male mice.

The generation of FSHR knockout mice (FORKO) provided additional insight into the dependence of spermatogenesis on FSH (Dierich et al. 1998, Abel et al. 2000). As with Fshb null males, FORKO males were fertile, with reduced testis size and decreased spermatogenesis. To examine key differences in these models, a study was conducted to directly compare the phenotypes observed of FORKO and FSH $\beta$ GM mice (Baker et al. 2003). Comparison of serum and intratesticular testosterone showed a reduced level of circulating testosterone in FORKO animals, which was not observed in the $\mathrm{FSH} \beta$ mouse model; yet both models exhibited diminished intra-testicular testosterone, indicating that local production of testosterone was impaired in both FORKO and FSH $\beta$ mice. Serum $\mathrm{LH}$ was elevated in FORKO animals, but not FSH $\beta$ animals. Interestingly, Leydig cell-specific steroidogenic genes such as Cyp11a1 were diminished in the FORKO model, with decreased Leydig cell number to $\sim 60 \%$ of control, suggesting a potential failure of Leydig cell proliferation and/or differentiation at puberty in FORKO animals, which was not observed in Fshb KO animals. This effect is likely to be reflective of the decreased Leydig cell number observed in these animals and represents a key difference between these animal models. As both models were fertile, these studies revealed that FSH action is not critical for the maintenance of foetal Leydig cells, as shortly after birth, when the maintenance of these cells is critically dependent on gonadotrophin action. As FSHR is expressed solely in Sertoli cells, the action of FSHR on Leydig cell development must be via Sertoli cell-secreted paracrine factors. Previously studies have implicated factors such as desert hedgehog and PDGF; however, to date nothing has conclusively been described to be the key factor(s) mediating these paracrine effects. It is likely that FSHR action mediates and ensures sufficient Sertoli cell activity for output of such trophic factors, and why spermatogenesis is impaired when either $\mathrm{FSH} \beta$ or FSHR action is abrogated. Whereas Fshb and Fshr KO male mice are fertile, there is some discrepancy in humans on the phenotype of men with inactivated FSH function. The three men described with inactivating $F S H B$ mutations are all azoospermic (Lindstedt et al. 1998, Phillip et al. 1998, Layman et al. 2002), whereas the five men with inactivating FSHR mutations have oligozoospermia of variable severity (Tapanainen et al. 1997). This discrepancy can be resolved only through detection of new cases of these extremely rare mutations.

\section{Conclusions and perspectives}

The precise and coordinated control of gonadotrophin actions is crucial for the maintenance of male 
reproductive functions. Modifications in these functions can result in impaired fertility, with chronic dysregulation of gonadotrophin action often resulting in sub- or infertility. Our understanding of the molecular mechanisms underlying human reproductive pathologies resulting from dysregulation of gonadotrophin action has been greatly enhanced by the generation and study of GM mouse models. The use of loss-of-function and gainof-function models enables us to probe both modest and chronic changes in gonadotrophin secretion and gonadotrophin receptor activity, providing key detail in the developmental programming of males. These models identify how fundamental temporal control of the hypothalamic-pituitary-gonadal axis co-ordinates the development and function of the Sertoli and Leydig cells, necessary for the production and maintenance of full spermatogenesis.

Comparative analysis of human and mouse reproductive pathologies shows us that Sertoli and Leydig cell function is highly sensitive to changes in gonadotrophin action, particularly LH/LHR. Clinical pathologies of enhanced $\mathrm{LH}$ action result in precocious puberty and Leydig cell hyperplasia; however, normal fertility is usually maintained in humans (Themmen \& Huhtaniemi 2000), as observed with the CAM LHR mouse model (McGee \& Narayan 2013). Many activating mutations of the LHR resulting in male reproductive pathologies have been identified, with the hotspots for activating mutations primarily localised to the $\mathrm{G}$ protein-coupling region of the receptor (Simoni et al. 1998). It is interesting to note the disparity between GM models with constitutively active LHR and increased circulating $\mathrm{LH} / \mathrm{hCG}$ in the timing of puberty. Precocious puberty was not observed in male mice with increased circulating $\mathrm{LH} / \mathrm{hCG}$ despite the pre-pubertal increase in testosterone observed in many of the GM models discussed. This may reflect differences in the regulatory and membrane trafficking mechanisms controlling the expression and activity of WT and constitutively active LHR. Indeed, in hCG $\alpha \beta$ mice, the WT LHR was subject to chronic down-regulation, while the constitutively active LHR may not be subject to such control. Unsurprisingly, only few activating mutations of FSHR have been identified in humans, probably due to the relatively benign phenotype observed (Gromoll et al. 1996, Casas-Gonzalez et al. 2012). Human males are fertile, mimicking the CAM FSHR mouse models described.

Although there are many similarities between human reproductive pathologies originating from the dysfunction of gonadotrophin/gonadotrophin receptor, and mouse models of the same origin, it should be noted that exceptions do exist and exact phenocopies of observed dysfunctions are not always observed between these species. Of notable difference are the mechanisms of prenatal and prepubertal development and the relative importance and contributions of gonadotrophin/gonadotrophin receptor function, particularly LH/LHR, to testicular development in these processes. That said, GM mouse models have been excellent tools for dissecting the molecular mechanisms underlying reproductive pathologies, underpinning many research efforts to understand the physiology of the function of gonadotrophins and their receptors.

With the ever-growing sophistication in GM approaches, allowing similar point mutations with human genetic diseases, and more targeted spatial and temporal integration, replacement or deletion and the coming of age of BAC transgenics, the use of mouse models provides new exciting opportunities to understand the mechanisms underlying reproductive pathologies. Whether mouse models can be used to test small molecule activators, inhibitors or pharmacochaperones of gonadotrophin receptor function is yet to be investigated. However, in vivo proof of concept studies with pharmacochaperone of the LHR (Newton et al. 2011) and of the GnRHR (Janovick et al. 2013) presents exciting opportunities and future directions in drug design, with the use of in vivo models providing important hypothesis testing tools for researchers for many years to come.

\section{Declaration of interest}

The authors declare that there is no conflict of interest that could be perceived as prejudicing the impartiality of the review.

\section{Funding}

This work was funded by the BBSRC project grant BB/1008004/1, the Wellcome Trust Program Grant 082101/ Z/07/Z and the Society for Endocrinology Early Career grant.

\section{References}

Abel MH, Wootton AN, Wilkins V, Huhtaniemi I, Knight PG \& Charlton HM 2000 The effect of a null mutation in the folliclestimulating hormone receptor gene on mouse reproduction. Endocrinology 141 1795-1803.

Ahtiainen P, Rulli SB, Shariatmadari R, Pelliniemi LJ, Toppari J, Poutanen M \& Huhtaniemi IT 2005 Fetal but not adult Leydig cells are susceptible to adenoma formation in response to persistently high hCG level: a study on hCG overexpressing transgenic mice. Oncogene 24 7301-7309. (doi:10.1038/sj.onc.1208893)

Allan CM, Haywood M, Swaraj S, Spaliviero J, Koch A, Jimenez $M$, Poutanen M, Levallet J, Huhtaniemi I, Illingworth P et al. 2001 A novel transgenic model to characterize the specific effects of folliclestimulating hormone on gonadal physiology in the absence of luteinizing hormone actions. Endocrinology 142 2213-2220.

Baker PJ, Pakarinen P, Huhtaniemi IT, Abel MH, Charlton HM, Kumar TR \& O'Shaughnessy PJ 2003 Failure of normal Leydig cell development in follicle-stimulating hormone $(\mathrm{FSH})$ receptor-deficient mice, but not FSH $\beta$-deficient mice: role for constitutive FSH receptor activity. Endocrinology 144 138-145. (doi:10.1210/en.2002-220637)

Casas-Gonzalez P, Scaglia HE, Perez-Solis MA, Durand G, Scaglia J, Zarinan T, Dias JA, Reiter E \& Ulloa-Aguirre A 2012 Normal testicular function without detectable follicle-stimulating hormone. A novel 
mutation in the follicle-stimulating hormone receptor gene leading to apparent constitutive activity and impaired agonist-induced desensitization and internalization. Molecular and Cellular Endocrinology 364 71-82. (doi:10.1016/j.mce.2012.08.011)

Cattanach BM, Iddon CA, Charlton HM, Chiappa SA \& Fink G 1977 Gonadotrophin-releasing hormone deficiency in a mutant mouse with hypogonadism. Nature 269 338-340. (doi:10.1038/269338a0)

Dierich A, Sairam MR, Monaco L, Fimia GM, Gansmuller A, LeMeur M \& Sassone-Corsi P 1998 Impairing follicle-stimulating hormone (FSH) signaling in vivo: targeted disruption of the FSH receptor leads to aberrant gametogenesis and hormonal imbalance. PNAS 95 13612-13617. (doi:10.1073/pnas.95.23.13612)

El-Gehani F, Zhang FP, Pakarinen P, Rannikko A \& Huhtaniemi I 1998 Gonadotropin-independent regulation of steroidogenesis in the fetal rat testis. Biology of Reproduction 58 116-123. (doi:10.1095/biolreprod58. 1.116)

Gonzalez B, Ratner LD, Di Giorgio NP, Poutanen M, Huhtaniemi IT, Calandra RS, Lux-Lantos VA \& Rulli SB 2011 Endogenously elevated androgens alter the developmental programming of the hypothalamicpituitary axis in male mice. Molecular and Cellular Endocrinology 332 78-87. (doi:10.1016/j.mce.2010.09.016)

Gromoll J, Simoni M \& Nieschlag E 1996 An activating mutation of the follicle-stimulating hormone receptor autonomously sustains spermatogenesis in a hypophysectomized man. Journal of Clinical Endocrinology and Metabolism 81 1367-1370.

Haywood M, Tymchenko N, Spaliviero J, Koch A, Jimenez M, Gromoll J, Simoni M, Nordhoff V, Handelsman DJ \& Allan CM 2002 An activated human follicle-stimulating hormone (FSH) receptor stimulates FSH-like activity in gonadotropin-deficient transgenic mice. Molecular Endocrinology 16 2582-2591. (doi:10.1210/me.2002-0032)

Huhtaniemi I, Ahtiainen P, Pakarainen T, Rulli SB, Zhang FP \& Poutanen M 2006 Genetically modified mouse models in studies of luteinising hormone action. Molecular and Cellular Endocrinology 252 126-135. (doi:10.1016/j.mce.2006.03.026)

Janovick JA, Stewart MD, Jacob D, Martin LD, Deng JM, Stewart CA, Wang Y, Cornea A, Chavali L, Lopez S et al. 2013 Restoration of testis function in hypogonadotropic hypogonadal mice harboring a misfolded GnRHR mutant by pharmacoperone drug therapy. PNAS $\mathbf{1 1 0}$ 21030-21035. (doi:10.1073/pnas.1315194110)

Kendal SK, Samuelson LC, Saunders TL, Wood RI \& Camper SA 1995 Targeted disruption of the pituitary glycoprotein hormone $\alpha$-subunit produces hypogonadal and hypothyroid mice. Genes and Development 9 2007-2019. (doi:10.1101/gad.9.16.2007)

Kumar TR, Wang Y, Lu N \& Matzuk MM 1997 Follicle stimulating hormone is required for ovarian follicle maturation but not male fertility. Nature Genetics 15 201-204. (doi:10.1038/ng0297-201)

Layman LC, Porto AL, Xie J, da Motta LA, da Motta LD, Weiser W \& Sluss PM 2002 FSH $\beta$ gene mutations in a female with partial breast development and a male sibling with normal puberty and azoospermia. Journal of Clinical Endocrinology and Metabolism 87 3702-3707.

Lei ZM, Mishra S, Zou W, Xu B, Foltz M, Li X \& Rao CV 2001 Targeted disruption of luteinizing hormone/human chorionic gonadotropin receptor gene. Molecular Endocrinology 15 184-200. (doi:10.1210/ mend.15.1.0586)

Lindstedt G, Nystrom E, Matthews C, Ernest I, Janson PO \& Chatterjee K 1998 Follitropin (FSH) deficiency in an infertile male due to $\mathrm{FSH} \beta$ gene mutation. A syndrome of normal puberty and virilization but underdeveloped testicles with azoospermia, low FSH but high lutropin and normal serum testosterone concentrations. Clinical Chemistry and Laboratory Medicine 36 663-665. (doi:10.1515/CCLM. 1998.118)

Ma X, Dong Y, Matzuk MM \& Kumar TR 2004 Targeted disruption of luteinizing hormone $\beta$-subunit leads to hypogonadism, defects in gonadal steroidogenesis, and infertility. PNAS 101 17294-17299. (doi:10.1073/pnas.0404743101)

Matzuk MM, DeMayo FJ, Hadsell LA \& Kumar TR 2003 Overexpression of human chorionic gonadotropin causes multiple reproductive defects in transgenic mice. Biology of Reproduction 69 338-346. (doi:10.1095/ biolreprod.102.013953)
McGee SR \& Narayan P 2013 Precocious puberty and Leydig cell hyperplasia in male mice with a gain of function mutation in the LH receptor gene. Endocrinology 154 3900-3913. (doi:10.1210/en. 2012-2179)

McLachlan RI, Wreford NG, Robertson DM \& de Kretser DM 1995 Hormonal control of spermatogenesis. Trends in Endocrinology and Metabolism 6 95-101. (doi:10.1016/1043-2760(94)00215-P)

Meehan TP \& Narayan P 2007 Constitutively active luteinizing hormone receptors: consequences of in vivo expression. Molecular and Cellular Endocrinology 260-262 294-300. (doi:10.1016/j.mce. 2006.03.045)

Meehan TP, Harmon BG, Overcast ME, Yu KK, Camper SA, Puett D \& Narayan P 2005 Gonadal defects and hormonal alterations in transgenic mice expressing a single chain human chorionic gonadotropin-lutropin receptor complex. Journal of Molecular Endocrinology 34 489-503. (doi:10.1677/jme.1.01669)

Mendelson C, Dufau M \& Catt K 1975 Gonadotropin binding and stimulation of cyclic adenosine $3^{\prime}, 5^{\prime}$-monophosphate and testosterone production in isolated Leydig cells. Journal of Biological Chemistry 250 8818-8823.

Newton CL, Whay AM, McArdle CA, Zhang M, van Koppen CJ, van de Lagemaat R, Segaloff DL \& Millar RP 2011 Rescue of expression and signaling of human luteinizing hormone $G$ protein-coupled receptor mutants with an allosterically binding small-molecule agonist. PNAS 108 7172-7176. (doi:10.1073/pnas.1015723108)

Oduwole OO, Vydra N, Wood NE, Samanta L, Owen L, Keevil B, Donaldson M, Naresh K \& Huhtaniemi IT 2014 Overlapping dose responses of spermatogenic and extragonadal testosterone actions jeopardize the principle of hormonal male contraception. FASEB Journal 28 2566-2576. (doi:10.1096/fj.13-249219)

Pakarainen T, Zhang FP, Makela S, Poutanen M \& Huhtaniemi I 2005 Testosterone replacement therapy induces spermatogenesis and partially restores fertility in luteinizing hormone receptor knockout mice. Endocrinology 146 596-606. (doi:10.1210/en.2004-0913)

Pakarainen T, Ahtiainen P, Zhang FP, Rulli S, Poutanen M \& Huhtaniemi I 2007 Extragonadal LH/hCG action - not yet time to rewrite textbooks. Molecular and Cellular Endocrinology 269 9-16. (doi:10.1016/j.mce. 2006.10.019)

Peltoketo H, Strauss L, Karjalainen R, Zhang M, Stamp GW, Segaloff DL, Poutanen M \& Huhtaniemi IT 2010 Female mice expressing constitutively active mutants of FSH receptor present with a phenotype of premature follicle depletion and estrogen excess. Endocrinology 151 1872-1883. (doi:10.1210/en.2009-0966)

Peltoketo H, Zhang FP \& Rulli SB 2011 Animal models for aberrations of gonadotropin action. Reviews in Endocrine \& Metabolic Disorders 12 245-258. (doi:10.1007/s11154-011-9174-4)

Phillip M, Arbelle JE, Segev Y \& Parvari R 1998 Male hypogonadism due to a mutation in the gene for the $\beta$-subunit of follicle-stimulating hormone. New England Journal of Medicine 338 1729-1732. (doi:10.1056/ NEJM199806113382404)

Risma KA, Clay CM, Nett TM, Wagner T, Yun J \& Nilson JH 1995 Targeted overexpression of luteinizing hormone in transgenic mice leads to infertility, polycystic ovaries, and ovarian tumors. PNAS 92 1322-1326. (doi:10.1073/pnas.92.5.1322)

Rulli SB, Ahtiainen P, Makela S, Toppari J, Poutanen M \& Huhtaniemi I 2003 Elevated steroidogenesis, defective reproductive organs, and infertility in transgenic male mice overexpressing human chorionic gonadotropin. Endocrinology 144 4980-4990. (doi:10.1210/en.20030403)

Sharpe RM, Kerr JB, McKinnell C \& Millar M 1994 Temporal relationship between androgen-dependent changes in the volume of seminiferous tubule fluid, lumen size and seminiferous tubule protein secretion in rats. Journal of Reproduction and Fertility 101 193-198. (doi:10.1530/jrf.0. 1010193)

Simoni M, Gromoll J \& Nieschlag E 1998 Molecular pathophysiology and clinical manifestations of gonadotropin receptor defects. Steroids $\mathbf{6 3}$ 288-293. (doi:10.1016/S0039-128X(98)00008-7)

Tapanainen JS, Aittomaki K, Min J, Vaskivuo T \& Huhtaniemi IT 1997 Men homozygous for an inactivating mutation of the follicle-stimulating hormone $(\mathrm{FSH})$ receptor gene present variable suppression of spermatogenesis and fertility. Nature Genetics 15 205-206. (doi:10.1038/ ng0297-205) 
Themmen APN \& Huhtaniemi IT 2000 Mutations of gonadotropins and gonadotropin receptors: elucidating the physiology and pathophysiology of pituitary-gonadal function. Endocrine Reviews 21 551-583. (doi:10.1210/edrv.21.5.0409)

Zhang FP, Poutanen M, Wilbertz J \& Huhtaniemi I 2001 Normal prenatal but arrested postnatal sexual development of luteinizing hormone receptor knockout (LuRKO) mice. Molecular Endocrinology 15 172-183. (doi:10.1210/mend.15.1.0582)

Zhang FP, Pakarainen T, Poutanen M, Toppari J \& Huhtaniemi I 2003 The low gonadotropin-independent constitutive production of testicular testosterone is sufficient to maintain spermatogenesis. PNAS $\mathbf{1 0 0}$ 13692-13697. (doi:10.1073/pnas.2232815100)
Zhang FP, Pakarainen T, Zhu F, Poutanen M \& Huhtaniemi I 2004 Molecular characterization of postnatal development of testicular steroidogenesis in luteinizing hormone receptor knockout mice. Endocrinology 145 1453-1463. (doi:10.1210/en.2003-1049)

Received 11 June 2014

First decision 24 June 2014

Revised manuscript received 3 July 2014

Accepted 15 July 2014 